\title{
Effect of oral sodium bicarbonate supplementation on progression of chronic kidney disease in patients with chronic metabolic acidosis: study protocol for a randomized controlled trial (SoBic-Study)
}

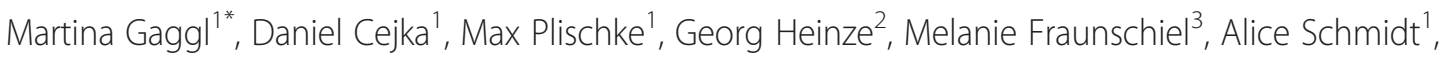
Walter $\mathrm{H} \mathrm{Hörl}^{1 \wedge}$ and Gere Sunder-Plassmann ${ }^{1}$

\begin{abstract}
Background: Overt chronic metabolic acidosis in patients with chronic kidney disease develops after a drop of glomerular filtration rate to less than approximately $25 \mathrm{~mL} / \mathrm{min} / 1.73 \mathrm{~m}^{2}$. The pathogenic mechanism seems to be a lack of tubular bicarbonate production, which in healthy individuals neutralizes the acid net production. As shown in several animal and human studies the acidotic milieu alters bone and vitamin D metabolism, induces muscle wasting, and impairs albumin synthesis, aside from a direct alteration of renal tissue by increasing angiotensin II, aldosteron and endothelin kidney levels. Subsequent studies testing various therapeutic approaches in very selected study populations showed that oral supplementation of the lacking bicarbonate halts progression of decline of renal function. However, due to methodological limitations of these studies further investigations are of urgent need to ensure the validity of this therapeutic concept.
\end{abstract}

Methods/Design: The SoBic-study is a single-center, randomized, controlled, open-label clinical phase IV study performed at the nephrological outpatient service of the Medical University of Vienna. Two-hundred patients classified to CKD stage 3 or 4 with two separate measurements of $\mathrm{HCO}_{3}^{-}$of $<21 \mathrm{mmol} / \mathrm{L}$ will be 1:1 randomized to either receive a high dose of oral sodium bicarbonate with a serum target $\mathrm{HCO}_{3}^{-}$level of $24 \pm 1 \mathrm{mmol} / \mathrm{L}$ or receive a rescue therapy of sodium bicarbonate with a serum target level of $20 \pm 1 \mathrm{mmol} / \mathrm{L}$. The follow up will be for two years. The primary outcome is the effect of sodium bicarbonate supplementation on renal function measured by means of estimated glomerular filtration rates (4-variable-MDRD-equation) after two years. Secondary outcomes are change in markers of bone metabolism between groups, death rates between groups, and the number of subjects proceeding to renal replacement therapy across groups. Adverse events, such as worsening of arterial hypertension due to the additional sodium consumption, will be accurately monitored.

Discussion: We hypothesize that sufficiently balanced acid-base homeostasis leads to a reduction of decline of renal function in patients with chronic kidney disease. The concept of an exogenous bicarbonate supplementation to substitute the lacking endogenous bicarbonate has existed for a long time, but has never been investigated sufficiently to state clear treatment guidelines.

Trial registration: EUDRACT Number: 2012-001824-36

Keywords: Metabolic acidosis, Chronic kidney disease, Kidney injury, Sodium bicarbonate, Acid-base balance, Acid retention, Acidotic, Progression

\footnotetext{
* Correspondence: Martina.gaggl@meduniwien.ac.at

Deceased

'Department of Medicine III, Division of Nephrology and Dialysis, Medical University of Vienna, Vienna, Austria

Full list of author information is available at the end of the article
} 


\section{Background}

Chronic kidney disease (CKD) occurs in approximately one in ten persons worldwide and represents not only a medical challenge but also a great socioeconomic burden. Major efforts have been made to investigate treatment options aiming to slow progression to end-stage renal disease (ESRD) and, subsequently, to reduce mortality in kidney patients. A renin-angiotensin system blockade with either angiotensin-I-converting enzyme inhibitors or angiotensin-II-receptor antagonists slows the progression of decline in renal function [1-5]. However, further therapeutic interventions have not shown any benefits [6-10]. The comprehensive summery by Fink et al. underscores the lack of evidence-based treatment concepts in CKD and even calls screening and monitoring for early-stage CKD into question [11].

Overt chronic metabolic acidosis in CKD patients develops after a drop in glomerular filtration rate (GFR) to less than approximately $25 \mathrm{~mL} / \mathrm{min} / 1.73 \mathrm{~m}^{2}$. The pathogenic mechanism seems to be a lack of tubular bicarbonate production, which in healthy individuals neutralizes the acid net production. As shown in several animal and human studies the acidotic milieu alters bone and vitamin D metabolism [12], induces muscle wasting [13], and impairs albumin synthesis [14], in addition to other detrimental effects [15,16]. Experiments in rats suggest that even in the earlier stages of CKD with serum bicarbonate levels within normal limits, increased per-nephron acidification occurs to obviate overt metabolic acidosis [17]. Investigations to elucidate the contribution to the progression of CKD itself have provided contradictory results [18-20]. However, there is evidence that the alternative complement system is activated by increased tubular ammonia production [21] and that endothelin, angiotensin II and aldosteron kidney concentrations are increased as a direct result of distal nephron acidification [17,20,22]. Taken together, these alterations induce tubulointerstitial scarring in the long term.

The results of several retrospective studies conducted in different types of populations showed clear associations between acid-base imbalance and increased mortality $[23,24]$. Above all is the recently published analysis of the CKD registry of the Cleveland Clinic health care provider in 41,749 patients with CKD stage III and IV (estimated (e) GFR of 60 to $15 \mathrm{~mL} / \mathrm{min} / 1.73 \mathrm{~m}^{2}$, measured by the Chronic Kidney Disease Epidemiology Collaboration equation). Adjusted for several covariates the all-cause mortality for subjects with a low serum bicarbonate level $(<23 \mathrm{mmol} / \mathrm{L})$ is $23 \%$ higher than for those with a level within the normal range (23 to $32 \mathrm{mmol} / \mathrm{L}$ ) [25].

The first prospective studies in closely selected study populations [26] using various therapeutic interventions [27] and endpoints revealed beneficial effects. In particular, de
Brito-Ashurst et al. showed that sodium bicarbonate supplementation in patients with CKD stage IV slows the decline in renal function, although the study comprised some serious methodological limitations [28].

In line with the aforementioned studies we assume that a sufficiently balanced acid-base status leads to a reduction in the decline of renal function in patients with CKD. Bicarbonate is necessary to counterbalance acid net production arising from protein metabolism and acid-rich diets. Thus, the intervention of exogenous bicarbonate supplementation to substitute the lacking endogenous bicarbonate would appear to be rational. This simple concept has existed for a long time, but has never been investigated sufficiently to state clear treatment guidelines for physicians. Furthermore, including patients with both moderate and severe grades of renal impairment represents a novel and comprehensive approach. Thus, conclusions drawn by results of this study are directly applicable to routine care and treatment guidelines.

\section{Methods/Design \\ Trial design}

The SoBic study is a single-center, randomized, controlled, stratified, open-label clinical phase IV study and will be performed at the Nephrological outpatient service of the Medical University of Vienna. From the beginning of October 2013, 200 subjects with CKD stage III and IV and chronic metabolic acidosis will be randomized to either receive a high dose of oral sodium bicarbonate with a serum target $\mathrm{HCO}_{3}^{-}$level of $24 \pm 1 \mathrm{mmol} / \mathrm{L}$ or receive a rescue therapy of sodium bicarbonate, if necessary, with a serum target level of $20 \pm 1 \mathrm{mmol} / \mathrm{L}$. The follow up period will be 2 years. The ethics committee of the Medical University of Vienna and the Austrian Competent Authority approved the study. The study is registered at the European Union Drug Regulating Authority (EUDRACT Number: 2012-001824-36; https://www.clinicaltrialsregister.eu) and will be conducted in accordance with the current version of the Declaration of Helsinki [29]. All study subjects will be appropriately insured and are required to give written informed consent before any study action is taken. Data will be stored in the Clincase version 2.6.0.33 clinical trial system (Quadratek Data Solutions Ltd, London, United Kingdom. Data structure design is developed by the science support work group of AKIM (Allgemeines Krankenhaus Informations Management) at the Center of Medical Statistics, Informatics and Intelligent Systems. The software provides advanced data management and data preparation tools for statistic evaluation. The webbased electronic case report forms allow efficient user handling and thus, error avoidance. In accordance with the Good Clinical Practice (GCP) guidelines an independent person will periodically perform data monitoring [30]. 
The study will be reported as suggested by the Consolidated Standards of Reporting Trials (CONSORT) 2010 guidelines [31].

\section{Participants}

The study population will comprise incident and prevalent patients with CKD from the outpatient service of a tertiary care facility. Patients classified as having CKD stage III or IV, and two separate measurements of $\mathrm{HCO}_{3}^{-}$of $<21 \mathrm{mmol} / \mathrm{L}$ (at least 1 day apart) will be included in the study. Patients fulfilling the inclusion criteria, who are already receiving alkali treatment, can be included after a wash-out phase of 4 weeks. The inclusion criteria are age over 18 years, renal function (measured by eGFR calculated by the four-variable Modification of Diet in Renal Disease (MDRD) study equation) between 60 and $15 \mathrm{~mL} /$ $\mathrm{min} / 1.73 \mathrm{~m}^{2}$, venous serum $\mathrm{HCO}_{3}^{-}$of $<21 \mathrm{mmol} / \mathrm{L}$ on two consecutive measurements (at least 1 day apart), and for the patient to be in a stable clinical condition. Patients with malignant disease or within 5 years of successful treatment of malignant disease (except dermal malignancies and carcinoma in situ of the cervix declared to be cured), and patients with morbid obesity (body mass index $>40 \mathrm{~kg} / \mathrm{m}^{2}$ ), chronic inflammation $(C$ reactive protein $>10 \mathrm{mg} / \mathrm{dL}$ ) or taking immunosuppressive therapy of any kind, poorly controlled blood pressure $(>150 / 90 \mathrm{mmHg}$ despite the use of four agents), overt congestive heart failure, or known peanut or soy allergy, will be excluded from the study.

With respect to concomitant medication, various drugs are known to induce metabolic acidosis [32]. However, most relevant with regard to the planned study are the phosphate binder sevelamer hydrochloride and potassiumsparing diuretics. Other agents known to neutralize metabolic acidosis, such as calcium citrate, sodium citrate and calcium carbonate are not allowed.

\section{Laboratory measurements}

Serum creatinine will be determined by means of the Jaffe method (reference range $<1.2 \mathrm{mg} / \mathrm{dL}, \mathrm{mg} / \mathrm{dL} \times$ $88.4=\mu \mathrm{mol} / \mathrm{L})$. Bicarbonate measurements will be performed in venous blood samples and determined by an ABL 700 Copenhagen Blood Gas Analyzer (Radiometer Copenhagen, Copenhagen, Denmark). Markers of bone metabolism (bone alkaline phosphatase, osteocalcin, ctelopeptide pyridinoline crosslinks of type I collagen, procollagen type I N-propeptide) will be measured as detailed in Cejka et al. [33]. All laboratory measurements, including urinalyses, will be performed in an ISO 9001-2008 certified and ISO 15189-accredited clinical laboratory at the Medical University Vienna [http://www.kimcl.at].

\section{Randomization and study visits}

Subjects will attend the clinic for a regular visit and blood draw. After a careful review of their medical history patients who fulfill the inclusion criteria will be contacted and informed about the study protocol. Patients who agree to participate in the study will be invited to a further blood work-up to ensure that metabolic acidosis is chronic rather than a one-time imbalance of the acid-base status. After obtaining written informed consent (day 0) each patient will be randomized 1:1 either to the treatment group or the control group (Figure 1). Subjects will be stratified for age $>60$ years and $\leq 60$ years [34], presence of diabetes mellitus (yes/no) [35], severe chronic metabolic acidosis (serum $\mathrm{HCO}_{3}^{-}<18 \mathrm{mmol} / \mathrm{L}$ ) versus moderate metabolic acidosis (serum $\mathrm{HCO}_{3}^{-} \geq 18 \mathrm{mmol} / \mathrm{L}$ ), and for previous alkali treatment (yes/no). Previous alkali treatment is defined as being continued for longer than 6 months (>25\% of the treatment period of the planned study) and serum $\mathrm{HCO}_{3}^{-} \geq 20 \mathrm{mmol} / \mathrm{L}$ on more than $75 \%$ of measurements. Stratified randomization will be carried out using the web-based randomizer program provided by the Medical University of Vienna [https://www.meduniwien.ac.at/ randomizer/web/login.php]. We use the minimization method with a preferred treatment probability of 0.9 , and a combination depth of 2.0, to guarantee that treatment allocation is balanced in all levels of the stratification factors, as well as in all pairwise combinations of stratification factors. After randomization, subjects will receive either the high dose of sodium bicarbonate or, if necessary, a low-dose rescue therapy with sodium bicarbonate.

Each study visit consists of a fasting blood draw (last food intake including the study medication should be at least 8 hours before) and urinalysis, measurement of vital signs, and assessment of changes in concomitant medication and adverse events (Table 1). At the beginning of the study a physical examination will be done and body weight and height will be assessed. Study visits will be performed at weeks 4, 8, 12, 20, 29, 38, 47, 60, 73, 86, and 104 .

\section{Intervention}

The initial and the maintenance dose for the intervention group will be determined based on the baseline $\mathrm{HCO}_{3}^{-}$level and the levels measured during follow up visits. Based on pilot data we expect the daily dose for the intervention group to vary between two and six capsules of Nephrotrans ${ }^{\oplus} 840 \mathrm{mg}$ (1,680 to 5,040 mg sodium bicarbonate per day). In the case of $\mathrm{HCO}_{3}^{-}$lower than $19 \mathrm{mmol} / \mathrm{L}$ at the baseline visit, or during follow up, subjects randomized to the control group will receive rescue therapy. We expect the daily dose to be zero to three capsules of Nephrotrans ${ }^{\oplus} 840 \mathrm{mg}$ (0 to 2,520 mg sodium bicarbonate per day) for the control group. After each study visit the study drug can be down- and uptitrated according to the actual $\mathrm{HCO}_{3}^{-}$level and the respective target value, as pre-specified at randomization, by means of the suggested treatment algorithm (Table 2A and $\mathrm{B})$. However, due to intra-individual differences in 


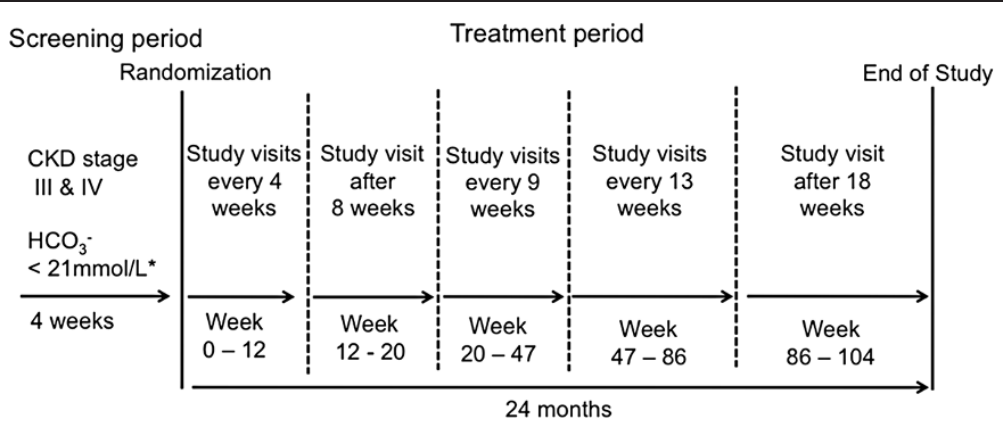

Figure 1 Study design. ${ }^{*}$ Two consecutive measurements at least 1 day apart. CKD, chronic kidney disease.

drug response the algorithm is not obligatory and might be modified if necessary to reach the target $\mathrm{HCO}_{3}^{-}$level for respective subjects.

\section{Outcome parameters}

The primary outcome is renal function and will be measured by means of eGFR, calculated according to the 4variable-MDRD Study equation [36].

Secondary outcomes are death, and the need for renal replacement therapy (RRT) (patients with renal transplantation, hemodialysis, peritoneal dialysis, and subjects who are in need of RRT, but personally elect not to start it). The need for RRT will be clinically evaluated, including monitoring of uremic symptoms (nausea and/or vomiting, fatigue, deterioration in nutritional status and significant weight loss, neuropathy, encephalopathy, or psychic disturbances), blood and fluid disturbances (volume overload, malignant hypertension, anemia, bleeding diathesis, pleuritis and/or pericarditis), and significant electrolyte imbalances. A further secondary outcome is the percent change in markers of bone metabolism (bone alkaline phosphatase, osteocalcin, c-telopeptide pyridinoline crosslinks of type I collagen, and procollagen type I N-propeptide) across groups.

\section{Sample size}

Assuming equal baseline levels of eGFR between the two study groups, a clinically relevant difference of $5 \mathrm{ml}$ in eGFR after 2 years, and an estimated standard deviation of $12 \mathrm{ml}$ for the change in eGFR after 2 years (pilot data, Figure 2), an independent sample $t$-test with a sample size of $2 \times 100$ patients will give $80 \%$ power to reach statistical significance at a two-sided significance level of $5 \%$.

\section{Statistical methods}

The intention-to-treat population will be used for statistical analysis. The primary analysis focuses on the estimated treatment effect at 2 years (difference between the two groups in eGFR after two years), which will be provided as the point estimate at the expected difference, $95 \%$ confidence interval and $P$-value. Mortality of patients or other reasons for dropout will be addressed by jointly modeling longitudinal eGFR and time to death using an appropriate joint model for longitudinal and time-to-event outcome [37]. In the longitudinal part of this model, a linear mixed model will be used with the repeated eGFR measurements as outcome values, and including as fixed factors treatment group, all stratification criteria (age, diabetes, severity of acidosis, previous alkali treatment), the eGFR baseline value and time since start of treatment, and a random intercept. An interaction effect (product term) of the treatment group and the time since start of treatment will also be included. Graphical diagnostic tools (residual plots) will be used to confirm the adequacy of model assumptions. A secondary outcome is time to death, compared between the treatment groups, which will also be estimated by the joint modeling approach. The time up to the point of need of RRT will be compared between the two treatment groups, accounting for death as a competing risk, by modeling the cumulative incidence function [38], including treatment group and the covariates age, diabetes, severity of acidosis and baseline eGFR. Percent change (from baseline to week 20 and baseline to week 104, respectively) in markers of bone metabolism will be analyzed by analysis of covariance, to adjust for sex, age, change in renal function, and baseline values of the bone markers. The incidence of serious adverse events will be reported and compared between groups using the chi-squared test. Baseline parameters (etiology of CKD, relevant medical disease, age, gender, concomitant medication, blood pressure, number of antihypertensive medications, and laboratory measurements) will be analyzed descriptively for the interventional and control group, respectively. SAS (Version 9.3, SAS Institute Inc., Cary, NC, USA, 2011) will be used for data management and analysis, and R 2.12.2/package JM [37] will be used for the main outcome analysis.

\section{Discussion}

In 1931 Lyon et al. described for the first time the simple approach of compensating metabolic acid excess in a 
Table 1 Visit and assessment schedule

\begin{tabular}{|c|c|c|c|c|c|c|c|c|c|c|c|c|c|}
\hline & \multicolumn{7}{|c|}{ Screening period (4 weeks) } & \multicolumn{6}{|c|}{ Treatment period (0 to 24 months) } \\
\hline & & Day 0 & $\begin{array}{c}\text { Week } 4 \\
\text { ( } \pm 2 \text { days) }\end{array}$ & $\begin{array}{c}\text { Week } 8 \\
( \pm 2 \text { days) }\end{array}$ & $\begin{array}{l}\text { Week } 12 \\
\text { ( } \pm 2 \text { days) }\end{array}$ & $\begin{array}{l}\text { Week } 20 \\
( \pm 5 \text { days) }\end{array}$ & $\begin{array}{l}\text { Week } 29 \\
( \pm 5 \text { days) }\end{array}$ & $\begin{array}{l}\text { Week } 38 \\
( \pm 5 \text { days) }\end{array}$ & $\begin{array}{l}\text { Week } 47 \\
( \pm 5 \text { days) }\end{array}$ & $\begin{array}{c}\text { Week } 60 \\
( \pm 10 \text { days })\end{array}$ & $\begin{array}{c}\text { Week } 73 \\
\text { ( } \pm 10 \text { days) }\end{array}$ & $\begin{array}{c}\text { Week } 86 \\
( \pm 10 \text { days) }\end{array}$ & $\begin{array}{l}\text { Week } 104 \\
( \pm 10 \text { days })\end{array}$ \\
\hline Visit & 1 & 2 & 3 & 4 & 5 & 6 & 7 & 8 & 9 & 10 & 11 & 12 & 13 \\
\hline Informed consent & & $x$ & & & & & & & & & & & \\
\hline Inclusion/exclusion criteria & $x$ & $x$ & & & & & & & & & & & \\
\hline Randomization & & $x$ & & & & & & & & & & & \\
\hline Medical history & & $x$ & & & & & & & & & & & $x$ \\
\hline Concomitant medication & & $x$ & $x$ & $x$ & $x$ & $x$ & $x$ & $x$ & $x$ & $x$ & $x$ & $x$ & $x$ \\
\hline Physical examination & & $x$ & & & & & & & & & & & $x$ \\
\hline Body weight and height & & $x$ & & & & & & & & & & & $x$ \\
\hline Vital signs (BP, PR) & & $x$ & $x$ & $x$ & $x$ & $x$ & $x$ & $x$ & $x$ & $x$ & $x$ & $x$ & $x$ \\
\hline Laboratory test & $x$ & $x$ & $x$ & $x$ & $x$ & $x$ & $x$ & $x$ & $x$ & $x$ & $x$ & $x$ & $x$ \\
\hline Laboratory test: bone markers & & $x$ & & & & $x$ & & & & & & & $x$ \\
\hline Biobank sample & & $x$ & & & & $x$ & & & $x$ & & $x$ & & $x$ \\
\hline Urinalysis & $x$ & $x$ & $x$ & $x$ & $x$ & $x$ & $x$ & $x$ & $x$ & $x$ & $x$ & $x$ & $x$ \\
\hline 24-hour urine collection & $x^{a}$ & $x^{a}$ & $x$ & & & $x$ & & & $x$ & & & & $x$ \\
\hline Urine pregnancy test $^{\mathrm{b}}$ & & $x$ & $x$ & $x$ & $x$ & $x$ & $x$ & $x$ & $x$ & $x$ & $x$ & $x$ & $x$ \\
\hline Adverse events & & & $x$ & $x$ & $x$ & $x$ & $x$ & $x$ & $x$ & $x$ & $x$ & $x$ & \\
\hline
\end{tabular}

${ }^{\mathbf{a}}$ To be performed either at screening visit 1 or screening visit 2. prior to randomization; ${ }^{\mathbf{b}}$ for females of childbearing age only. $\mathrm{BP}$, blood pressure; $\mathrm{PR}$, pulse rate. 
Table 2 Study drug up- and down-titration

\begin{tabular}{|c|c|c|}
\hline \multirow[b]{2}{*}{ (A) Baseline treatment algorithm } & \multicolumn{2}{|c|}{ Daily sodium bicarbonate (Nephrotrans ${ }^{\circledR} 840 \mathrm{mg}$ ) dosage } \\
\hline & Investigational group & Control group \\
\hline \multicolumn{3}{|l|}{ Mean $\mathrm{HCO}_{3}^{-}$of two measurements } \\
\hline$<18 \mathrm{mmol} / \mathrm{L}$ & 5,040 mg (2 capsules TID) & 2,520 mg (1 capsule TID) \\
\hline 18 to $19 \mathrm{mmol} / \mathrm{L}$ & 4,200 mg (2 capsules BID, 1 capsule QD) & $1,680 \mathrm{mg}$ (1 capsule BID) \\
\hline 19.1 to $20.0 \mathrm{mmol} / \mathrm{L}$ & 2,520 mg (1 capsule TID) & Monitor \\
\hline$>20 \mathrm{mmol} / \mathrm{L}$ & 1,680 mg (1 capsule BID) & \\
\hline (B) Follow-up visit treatment algorithm & \multicolumn{2}{|l|}{ Investigational group and control group } \\
\hline \multicolumn{3}{|l|}{ Difference to target $\mathrm{HCO}_{3}^{-}$level } \\
\hline$-1 \mathrm{mmol} / \mathrm{L}$ & \multicolumn{2}{|c|}{ Add $1,680 \mathrm{mg}$ to the previous daily dosage ( +1 capsule BID) } \\
\hline$-2 \mathrm{mmol} / \mathrm{L}$ & \multicolumn{2}{|c|}{ Add $3,360 \mathrm{mg}$ to the previous daily dosage ( +2 capsules BID) } \\
\hline$\leq-3 \mathrm{mmol} / \mathrm{L}$ & \multicolumn{2}{|c|}{ Add 5,040 mg to the previous daily dosage ( +2 capsules TID) } \\
\hline$+1 \mathrm{mmol} / \mathrm{L}$ & \multicolumn{2}{|c|}{ Subduct $1,680 \mathrm{mg}$ from the previous daily dosage (-2 capsules) } \\
\hline$+2 \mathrm{mmol} / \mathrm{L}$ & \multicolumn{2}{|c|}{ Subduct $3,360 \mathrm{mg}$ from the previous daily dosage ( -4 capsules) } \\
\hline$\geq+3 \mathrm{mmol} / \mathrm{L}$ & \multicolumn{2}{|c|}{ Subduct $5,040 \mathrm{mg}$ from the previous daily dosage (-6 capsules) } \\
\hline
\end{tabular}

QD, every day; BID, twice daily; TID, trice daily.

series of 17 patients with chronic nephritis by providing an alkaline diet or substituting alkaline salts [39]. In 2012 the question of whether or not systematic treatment of metabolic acidosis in CKD is indicated is still to be addressed by the scientific community, due to the paucity of acceptable evidence [40-42].

Indeed, patients with CKD comprise a difficult study cohort in terms of sample size calculation and accurate methodological planning, due to severe comorbidities and increased mortality [25,43-47]. De Brito-Ashurst et al. [28] tried to show that correcting metabolic acidosis stabilizes renal function in patients with CKD stage IV. In the open-label study the control group had a significantly greater decline in creatinine clearance (5.93 $\mathrm{mL} / \mathrm{min}$ ) compared to the treatment group $(1.88 \mathrm{~mL} / \mathrm{min})$ after 2 years. Furthermore, subjects in the treatment group presented with significantly slower progression of CKD (defined as creatinine clearance loss $>3 \mathrm{~mL} / \mathrm{min} /$ year) (9\% versus $45 \%$ in the control group). However, critical issues concerning the study methodology are that first, rapid progression and development of ESRD are competing endpoints, and second, the way this was handled in the data analysis is unclear. They stated that the rate of decline of creatinine clearance was similar between the two groups up to 12 months of follow-up because of dropout of 17 patients of the control group who had rapid decline and reached ESRD between 6 and 12 months'. However, only 15 dropouts are depicted in the respective Kaplan-Meier curve (Figure three in de Brito-Ashurst et al. [28]) between months 6 and 12. This might be the source of confounding and can be avoided by using a more appropriate competing endpoint analysis [48]. Further, the need of that additional endpoint is questionable, because subjects with rapid decline in renal function essentially reach ESRD at some point in time. Also, the control group was treated with 'standard care' with no further explanation whether that protocol included sodium bicarbonate supplementation. If this was not the case, the administration of placebo in the control group might have been indicated.

Mahajan et al. [26] recently compared the effect of sodium bicarbonate, sodium chloride and placebo on GFR in patients with early hypertensive nephropathy over 5 years. This was a randomized blinded trial in patients with CKD stage II, hypertension and albuminuria (200 to $2,000 \mathrm{mg} / \mathrm{g}$ creatinine), but normal plasma total carbon dioxide levels (equivalent to serum bicarbonate concentrations). Although the study population showed no biochemical signs of metabolic acidosis the supplementation of sodium bicarbonate was beneficial in terms of renal function: the rate of change of eGFR in the sodium bicarbonate group was $-1.47 \pm 0.19$ compared to $-2.13 \pm$ $0.19(P<0.014)$ in the placebo group and $-2.05 \pm$ $0.19 \mathrm{~mL} / \mathrm{min} / 1.73 \mathrm{~m}^{2}$ per year $(P<0.029)$ in the sodium chloride group. This gives good evidence that sodium bicarbonate supplementation provides positive effects on renal function on the one hand, but on the other only for that very selected cohort of patients with well-preserved renal function and albuminuria. Unfortunately, one cannot conclude that in patients with advanced renal injury and low GFR the therapeutic intervention would lead to the same outcome.

Another study, although designed to investigate the mechanism of preventing renal injury by oral sodium citrate, showed that treating metabolic acidosis in patients with CKD slows the decline of renal function (sodium citrate versus control: eGFR $-1.60 \pm 0.13$ versus $-3.79 \pm$ $0.30 \mathrm{~mL} / \mathrm{min} / 1.73 \mathrm{~m}^{2}$ per year, $P<0.0001$ ) [27]. We 


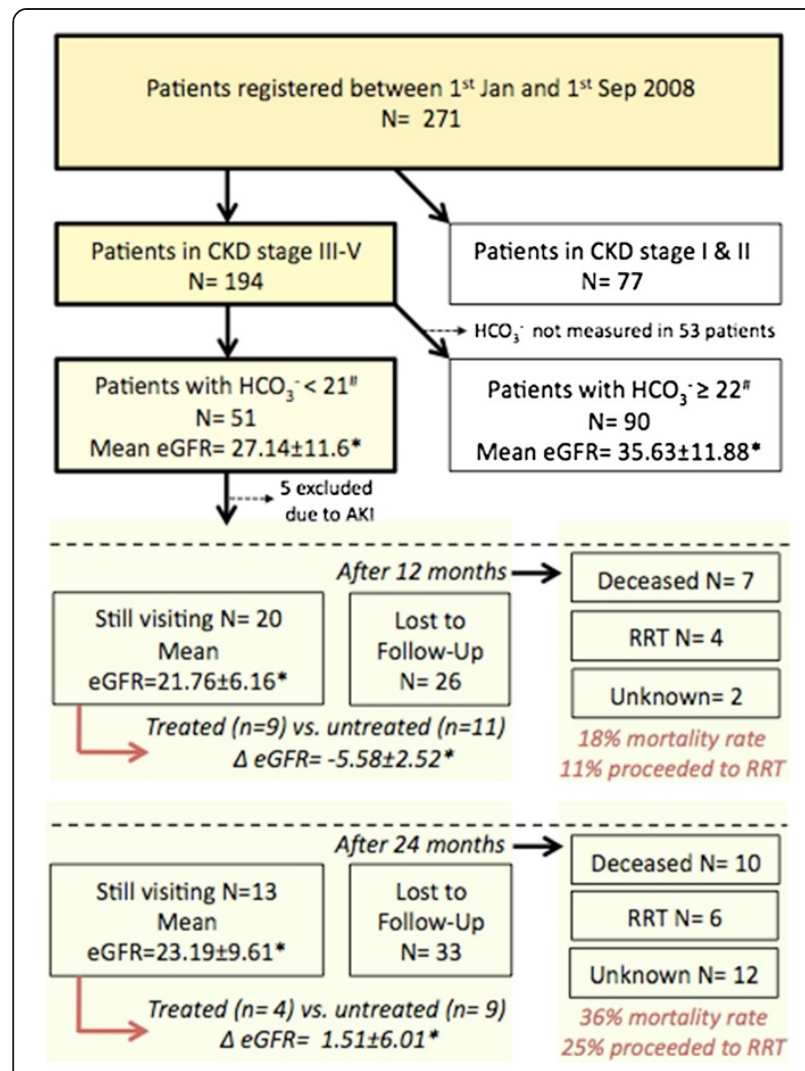

Figure 2 Cohort analyzed to calculate the sample size. CKD, chronic kidney disease; eGFR, estimated glomerular filtration rate.

refrain from using this agent to treat metabolic acidosis in our study patients due to the known increased aluminum absorption in combination with sodium citrate [49].

Furthermore, studies in animals and humans suggest that an acid-reduced diet may improve kidney function equally to supplementation with bicarbonate by means of tablets [50]. However, base-inducing diets predominantly include vegetables and fruits, which contain high amounts of potassium. In the long term, however, subjects with preserved renal function, who are not prone to hyperkalemia, might benefit tremendously from baserich diets over the commonly preferred acid-inducing diet of our society [51,52].

With regard to the presented study protocol we opted for an open-label approach, predominantly because to some extent sodium bicarbonate is included in standard routine care. Withdrawing that therapeutic intervention from study subjects could be deemed unethical. Aside from ethical reasons, the dose of the study drug in the interventional group is not fixed and administering an average amount of placebo tablets to the control group is also questionable. Moreover, given the relatively narrow range of suggested optimal $\mathrm{HCO}_{3}^{-}$levels and the distinct between-subject difference in response to treatment, blood levels have to be maintained regularly. Blinding of these laboratory results would have caused a disproportionately high amount of effort and cost compared to its benefits.

With regard to the intervention itself, sodium bicarbonate supplementation represents a simple therapeutic maneuver to restore acid-base balance in CKD patients. Few adverse events are reported in combination with oral sodium bicarbonate supplementation. Abdominal bloating would appear to be innocuous as it can be avoided by dividing the daily dosage into several smaller portions.

A mentionable concern is the additional sodium consumption evoked by the study medication. For each $100 \mathrm{mg}$ of sodium bicarbonate the additional sodium intake is approximately $27.4 \mathrm{mg}$. Dietary sodium intake is known to negatively influence arterial hypertension, therefore, blood pressure should be carefully monitored and if necessary, treated with antihypertensive agents. Notably, none of the studies performed in humans have noticed worsening of arterial hypertension in relation to the sodium bicarbonate supplementation. Nevertheless, this adverse event is reported for animal experiments [18]. However, former investigations suggested that the blood pressure-elevating effect is led by chloride and not by sodium. Although sodium retention and weight gain was similar across study groups an increase in arterial blood pressure could not be detected in subjects ingesting additional dietary sodium bound to an alternative anion than chloride [53-55]. In addition, there is a theoretical concern that long-term sodium bicarbonate intake may favor the development of calcium phosphate- and magnesium phosphate stones in the urinary tract, but so far this has not been observed in humans.

A single study was performed in cultured cells and uremic rats to investigate whether sodium bicarbonate supplementation affects the pathologic calcification of blood vessels. De Solis et al. reported that acid media prevented calcification of cultured vascular smooth muscle cells, and that uremic rats treated with sodium bicarbonate had a significantly higher aortic calcification index [56]. Given all the evidence of positive alteration by the supplementation of sodium bicarbonate, these concerns need to be kept in mind, and blood pressure will be closely monitored during the follow up period.

Taken together, previous studies, including observational and animal studies, give confidence that simply supplementing sodium bicarbonate in patients with CKD of any degree could positively alter decline in renal function. Possible adverse events are within the acceptable ratio of benefit to risk, however, adverse events will be followed closely in the study participants.

In summary, we believe that a clinical investigation to elucidate the effect of sodium bicarbonate supplementation in patients with metabolic acidosis and advanced CKD is of urgent need to develop a proper treatment 
strategy for those patients. This would not only improve the prognosis for each individual patient, but also help to decrease health care expenses, as sodium bicarbonate represents a relatively cheap treatment option.

\section{Trial status}

\section{Recruitment is planned to start in October 2013.}

\section{Abbreviations}

AKIM: Allgemeines Krankenhaus informations management; CKD: Ahronic kidney disease; CONSORT: Consolidated standards of reporting trials; eGFR: Estimated GFR; ESRD: End-stage renal disease; EUDRACT: European union drug regulating authority; GFR: Glomerular filtration rate; GCP: Good clinical practice; MDRD: Modification of diet in renal disease; RRT: Renal replacement therapy.

\section{Competing interests}

The authors declare that they have no competing interests.

\section{Authors' contributions}

MG and GSP designed the study, wrote the study protocol and manuscript, organized the funding, and will conduct the study. GH designed the study with regard to the statistical methodology and will perform randomization and stratification procedures and will perform the statistical analysis. MF programmed the electronic case report forms and will regularly maintain the database. DC, WHH, MP and AS contributed to the planning of the study and critically revised the manuscript. All authors read and approved the final manuscript.

\section{Authors' information}

We are saddened by the sudden passing of our department head and teacher, Prof. DDr. Walter H. Hörl FRCP, whom we want to dedicate this manuscript.

\section{Funding}

Study medication will be provided by the manufacturer MEDICE Pharma Pütter GmbH \& Co. KG without financial compensation.

\section{Author details}

'Department of Medicine III, Division of Nephrology and Dialysis, Medical University of Vienna, Vienna, Austria. ${ }^{2}$ Center of Medical Statistics, Informatics and Intelligent Systems, Section of Clinical Biometrics, Medical University of Vienna, Vienna, Austria. ${ }^{3}$ Center of Medical Statistics, Informatics and Intelligent Systems, Section for Medical Information Management and Imaging, Medical University of Vienna, Vienna, Austria.

\section{Received: 28 November 2012 Accepted: 17 June 2013}

Published: 4 July 2013

\section{References}

1. Parving HH, Lehnert H, Brochner-Mortensen J, Gomis R, Andersen S, Arner P: The effect of irbesartan on the development of diabetic nephropathy in patients with type 2 diabetes. N Engl J Med 2001, 345:870-878.

2. Brenner BM, Cooper ME, de Zeeuw D, Keane WF, Mitch WE, Parving HH, Remuzzi G, Snapinn SM, Zhang Z, Shahinfar S: Effects of losartan on renal and cardiovascular outcomes in patients with type 2 diabetes and nephropathy. N Engl J Med 2001, 345:861-869.

3. Ruggenenti P, Perna A, Mosconi L, Matalone M, Garini G, Salvadori M, Zoccali C, Scolari F, Maggiore Q, Tognoni G, Remuzzi G: Randomised placebo-controlled trial of effect of ramipril on decline in glomerular filtration rate and risk of terminal renal failure in proteinuric, nondiabetic nephropathy. The GISEN Group (Gruppo Italiano di Studi Epidemiologici in Nefrologia). Lancet 1997, 349:1857-1863.

4. Ruggenenti P, Perna A, Gherardi G, Garini G, Zoccali C, Salvadori M, Scolari F, Schena FP, Remuzzi G: Renoprotective properties of ACE-inhibition in non-diabetic nephropathies with non-nephrotic proteinuria. Lancet 1999, 354:359-364.

5. Hostetter TH: Prevention of end-stage renal disease due to type 2 diabetes. N Engl J Med 2001, 345:910-912.
6. Appel $\mathrm{L}$, Wright JT Jr, Greene T, Agodoa LY, Astor BC, Bakris GL, Cleveland WH, Charleston J, Contreras G, Faulkner ML, Gabbai FB, Gassman JJ, Hebert LA, Jamerson KA, Kopple JD, Kusek JW, Lash JP, Lea JP, Lewis JB, Lipkowitz MS, Massry SG, Miller ER, Norris K, Phillips RA, Pogue VA, Randall OS, Rostand SG, Smogorzewski MJ, Toto RD, Wang X: Intensive blood-pressure control in hypertensive chronic kidney disease. N Engl J Med 2010, 363:918-929.

7. Mann JF, Schmieder RE, McQueen M, Dyal L, Schumacher H, Pogue J, Wang X, Maggioni A, Budaj A, Chaithiraphan S, Dickstein K, Keltai M, Metsarinne K, Oto A, Parkhomenko A, Piegas LS, Svendsen TL, Teo KK, Yusuf S: Renal outcomes with telmisartan, ramipril, or both, in people at high vascular risk (the ONTARGET study): a multicentre, randomised, double-blind, controlled trial. Lancet 2008, 372:547-553.

8. Tobe SW, Clase CM, Gao P, McQueen M, Grosshennig A, Wang X, Teo KK, Yusuf S, Mann JF: Cardiovascular and renal outcomes with telmisartan, ramipril, or both in people at high renal risk: results from the ONTARGET and TRANSCEND studies. Circulation 2011, 123:1098-1107.

9. Ruggenenti P, Perna A, Tonelli M, Loriga G, Motterlini N, Rubis N, Ledda F, Rota S Jr, Satta A, Granata A, Battaglia G, Cambareri F, David S, Gaspari F, Stucchi N, Carminati S, Ene-lordache B, Cravedi P, Remuzzi G: Effects of add-on fluvastatin therapy in patients with chronic proteinuric nephropathy on dual renin-angiotensin system blockade: the ESPLANADE trial. Clin J Am Soc Nephrol 2010, 5:1928-1938.

10. Klahr S, AS L, Beck GJ, Caggiula AW, Hunsicker L, Kusek JW, Striker G: The effects of dietary protein restriction and blood-pressure control on the progression of chronic renal disease. Modification of diet in renal disease study group. N Engl J Med 1994, 330:877-884.

11. Fink HA, Ishani A, Taylor BC, Greer NL, MacDonald R, Rossini D, Sadiq S, Lankireddy S, Kane RL, Wilt TJ: Screening for, monitoring, and treatment of chronic kidney disease stages 1 to 3: a systematic review for the U.S. Preventive services task force and for an American College of Physicians clinical practice guideline. Ann Intern Med 2012, 156:570-581.

12. Kopple JD, Kalantar-Zadeh K, Mehrotra R: Risks of chronic metabolic acidosis in patients with chronic kidney disease. Kidney Int 2005, 67(Suppl 95):21-27.

13. Lim VS, Yarasheski KE, Flanigan MJ: The effect of uraemia, acidosis, and dialysis treatment on protein metabolism: a longitudinal leucine kinetic study. Nephrol Dial Transplant 1998, 13:1723-1730.

14. Movilli E, Zani R, Carli O, Sangalli L, Pola A, Camerini C, Cancarini GC, Scolari $F$, Feller P, Maiorca R: Correction of metabolic acidosis increases serum albumin concentrations and decreases kinetically evaluated protein intake in haemodialysis patients: a prospective study. Nephrol Dial Transplant 1998, 13:1719-1722.

15. Kraut JA, Madias NE: Consequences and therapy of the metabolic acidosis of chronic kidney disease. Pediatr Nephrol 2011, 26:19-28.

16. Kraut JA, Kurtz I: Metabolic acidosis of CKD: diagnosis, clinical characteristics, and treatment. Am J Kidney Dis 2005, 45:978-993.

17. Wesson $\mathrm{DE}$, Jo CH, Simoni J: Angiotensin II receptors mediate increased distal nephron acidification caused by acid retention. Kidney Int 2012, 82:1184-1194

18. Gadola L, Noboa O, Marquez MN, Rodriguez MJ, Nin N, Boggia J, Ferreiro A, Garcia S, Ortega V, Musto ML, Ponte P, Sesser P, Pizarrosa C, Ravaglio S, Vallega A: Calcium citrate ameliorates the progression of chronic renal injury. Kidney Int 2004, 65:1224-1230.

19. Jara A, Felsenfeld AJ, Bover J, Kleeman CR: Chronic metabolic acidosis in azotemic rats on a high-phosphate diet halts the progression of renal disease. Kidney Int 2000, 58:1023-1032.

20. Wesson $D E$, Simoni J: Acid retention during kidney failure induces endothelin and aldosterone production which lead to progressive GFR decline, a situation ameliorated by alkali diet. Kidney Int 2010, 78:1128-1135.

21. Nath KA, Hostetter MK, Hostetter TH: Pathophysiology of chronic tubulo-interstitial disease in rats. Interactions of dietary acid load, ammonia, and complement component C3. J Clin Invest 1985, 76:667-675.

22. Phisitkul S, Hacker C, Simoni J, Tran RM, Wesson DE: Dietary protein causes a decline in the glomerular filtration rate of the remnant kidney mediated by metabolic acidosis and endothelin receptors. Kidney Int 2008, 73:192-199.

23. Kovesdy CP, Anderson JE, Kalantar-Zadeh K: Association of serum bicarbonate levels with mortality in patients with non-dialysis-dependent CKD. Nephrol Dial Transplant 2009, 24:1232-1237.

24. Shah SN, Abramowitz M, Hostetter TH, Melamed ML: Serum bicarbonate levels and the progression of kidney disease: a cohort study. Am J Kidney Dis 2009, 54:270-277. 
25. Navaneethan SD, Schold JD, Arrigain S, Jolly SE, Wehbe E, Raina R, Simon JF, Srinivas TR, Jain A, Schreiber MJ Jr, Nally JV Jr: Serum Bicarbonate and Mortality in Stage 3 and Stage 4 Chronic Kidney Disease. Clin J Am Soc Nephrol 2011, 6:2395-2402

26. Mahajan A, Simoni J, Sheather SJ, Broglio KR, Rajab MH, Wesson DE: Daily oral sodium bicarbonate preserves glomerular filtration rate by slowing its decline in early hypertensive nephropathy. Kidney Int 2010, 78:303-309.

27. Phisitkul S, Khanna A, Simoni J, Broglio K, Sheather S, Rajab MH, Wesson DE: Amelioration of metabolic acidosis in patients with low GFR reduced kidney endothelin production and kidney injury, and better preserved GFR. Kidney Int 2010, 77:617-623.

28. de Brito-Ashurst I, Varagunam M, Raftery MJ, Yaqoob MM: Bicarbonate supplementation slows progression of CKD and improves nutritional status. J Am Soc Nephrol 2009, 20:2075-2084.

29. WMA: WMA declaration of Helsinki - Ethical principles for medical research involving human subjects. 2008. http://www.wma.net/en/30publications/ 10policies/b3/index.html.

30. EMEA: Guideline for good clinical practice ICH topic E 2002, 6, Step 5. http://www.ema.europa.eu/docs/en_GB/document_library/Scientific_ guideline/2009/09/WC500002874.pdf.

31. Moher D, Hopewell S, Schulz KF, Montori V, Gotzsche PC, Devereaux PJ, Elbourne D, Egger M, Altman DG: CONSORT 2010 explanation and elaboration: updated guidelines for reporting parallel group randomised trials. J Clin Epidemiol 2010, 2010:e1-e37.

32. Liamis G, Milionis HJ, Elisaf M: Pharmacologically-induced metabolic acidosis: a review. Drug Saf 2010, 33:371-391.

33. Cejka D, Jager-Lansky A, Kieweg H, Weber M, Bieglmayer C, Haider DG, Diarra D, Patsch JM, Kainberger F, Bohle B, Haas M: Sclerostin serum levels correlate positively with bone mineral density and microarchitecture in haemodialysis patients. Nephrol Dial Transplant 2012, 27:226-230.

34. Frassetto LA, Morris RC Jr, Sebastian A: Effect of age on blood acid-base composition in adult humans: role of age-related renal functional decline. Am J Physiol 1996, 271:F1114-F1122.

35. Caravaca F, Arrobas M, Pizarro JL, Esparrago JF: Metabolic acidosis in advanced renal failure: differences between diabetic and nondiabetic patients. Am J Kidney Dis 1999, 33:892-898.

36. Manjunath G, Sarnak MJ, Levey AS: Prediction equations to estimate glomerular filtration rate: an update. Curr Opin Nephrol Hypertens 2001, 10:785-792.

37. Rizopulos DJ: An R Package for the joint modelling of longitudinal and time-to-event data. J Stat Software 2010, 35:1-33.

38. Fine J, Gray R: A Proportional hazards model for the subdistribution of a competing risk. J Am Stat Assoc 1999, 94:496-509.

39. Lyon MD, Dunlop DM, Stewart CP: The alkaline treatment of chronic nephritis. Lancet 1931, 2:1009-1013.

40. Sahni V, Rosa RM, Batlle D: Potential benefits of alkali therapy to prevent GFR loss: time for a palatable 'solution' for the management of CKD. Kidney Int 2010, 78:1065-1067.

41. Abboud H, Henrich WL: Clinical practice. Stage IV chronic kidney disease. N Engl J Med 2010, 362:56-65.

42. Frassetto LA, Hsu CY: Metabolic acidosis and progression of chronic kidney disease. J Am Soc Nephrol 2009, 20:1869-1870.

43. John $\mathrm{R}$, Webb M, Young A, et al: Unreferred chronic kidney disease: a longitudinal study. Am J Kidney Dis 2004, 43:825-835.

44. Conway B, Webster A, Ramsay G, Morgan N, Neary J, Whitworth C, Harty J: Predicting mortality and uptake of renal replacement therapy in patients with stage 4 chronic kidney disease. Nephrol Dial Transplant 2009, 24:1930-1937

45. Levin A, Djurdjev O, Beaulieu M, Er L: Variability and risk factors for kidney disease progression and death following attainment of stage 4 CKD in a referred cohort. Am J Kidney Dis 2008, 52:661-671.

46. Holland DC, Lam M: Predictors of hospitalization and death among pre-dialysis patients: a retrospective cohort study. Nephrol Dial Transplant 2000, 15:650-658.

47. Go AS, Chertow GM, Fan D, McCulloch CE, Hsu CY: Chronic kidney disease and the risks of death, cardiovascular events, and hospitalization. $N$ Engl $J$ Med 2004, 351:1296-1305.

48. Agarwal R, Bunaye Z, Bekele DM, Light RP: Competing risk factor analysis of end-stage renal disease and mortality in chronic kidney disease. Am J Nephrol 2008, 28:569-575.
49. Nolan CR, Califano JR, Butzin CA: Influence of calcium acetate or calcium citrate on intestinal aluminum absorption. Kidney Int 1990, 38:937-941.

50. Goraya N, Simoni J, Jo C, Wesson DE: Dietary acid reduction with fruits and vegetables or bicarbonate attenuates kidney injury in patients with a moderately reduced glomerular filtration rate due to hypertensive nephropathy. Kidney Int 2012, 81:86-93.

51. Krishnamurthy VM, Wei G, Baird BC, Murtaugh M, Chonchol MB, Raphael KL, Greene T, Beddhu S: High dietary fiber intake is associated with decreased inflammation and all-cause mortality in patients with chronic kidney disease. Kidney Int 2012, 81:300-306.

52. Goraya N, Wesson DE: Acid-base status and progression of chronic kidney disease. Curr Opin Nephrol Hypertens 2012, 21:552-556.

53. Whitescarver SA, Ott CE, Jackson BA, Guthrie GP Jr, Kotchen TA: Salt-sensitive hypertension: contribution of chloride. Science 1984, 223:1430-1432.

54. Kurtz TW, Al-Bander HA Jr, Morris RC: "Salt-sensitive" essential hypertension in men. Is the sodium ion alone important? N Engl J Med 1987, 317:1043-1048.

55. Shore AC, Markandu ND, MacGregor GA: A randomized crossover study to compare the blood pressure response to sodium loading with and without chloride in patients with essential hypertension. $J$ Hypertens 1988, 6:613-617.

56. de Solis AJ, Gonzales-Pacheco FR, Deudero JJ, Neria F, Albalate M, Petkov V, Susanibar L, Fernandez-Sanchez R, Calabia O, Ortiz A, Caramelo C: Alkalinization potentiates vascular calcium deposition in an uremic milieu. J Nephrol 2009, 22:647-653.

doi:10.1186/1745-6215-14-196

Cite this article as: Gaggl et al:: Effect of oral sodium bicarbonate supplementation on progression of chronic kidney disease in patients with chronic metabolic acidosis: study protocol for a randomized controlled trial (SoBic-Study). Trials 2013 14:196.

\section{Submit your next manuscript to BioMed Central and take full advantage of:}

- Convenient online submission

- Thorough peer review

- No space constraints or color figure charges

- Immediate publication on acceptance

- Inclusion in PubMed, CAS, Scopus and Google Scholar

- Research which is freely available for redistribution

Submit your manuscript at www.biomedcentral.com/submit
C BioMed Central 